MONTHLY SCIENTIFIC TECHNICAL

AND INDUSTRIAL JOURNAL

"Без светоча науки

и с нертьн будуm nотемки»

A.И. Менделеев

\section{PEААКШИОННАЯ КОМЕГИЯ}

В.Н. ЗВЕРЕВА (главный редактор)

H.H. АНДРЕEВA

И.С. АФАНАСЬЕВ

А.В. АРЖИЛОВСКИЙ

М.Д. ВАЛЕЕВ

Э.Х. ВЕКИЛОВ

М.Г. ВОЛКОВ

А.В. ВолОхОв

А.Г. ГУМЕРОВ

А.Н. ДМИТРИЕВСКИЙ

А.Н. ДРОЗДОВ

С.А. ЖДАНОВ

И.С. ЗАКИРОВ

А.Б. ЗОЛОТУХИН

Р.P. ИБАТУЛЛИН

Н.Г. ИБРАГИМОВ

В.А. КЛИНЧЕВ

А.Ю. КОРШУНОВ

Н.И. КРЫСИН

В.3. КУЗЕНКОВ

А.М. КУЗНЕЦОВ

A.M. МАСТЕПАНОВ

A.Г. MECCEP

Н.Н. МИХАЙЛОВ

P.Х. МУСЛИМОВ

Д.К. НУРГАЛИЕВ

В.А. САВЕЛЬЕВ

Р.3. САХАБУТДИНОВ

А.С. ТИМЧУК

М.М. ХАСАНОВ

А.Х. ШАХВЕРДИЕВ

Г.И. ШМАЛЬ

Учрелители

журнала «НЕФТЯНОЕ ХОЗЯЙСТВО»

ПАО "НК "РоснеФТЬ"

АO "Зарубежнефть"

ПАО "ТатнефТь"

ПАО АНК "Башнефть"

АО РМНТК "Нефтеотдача"

НТО НГ им. акад. И.М. Губкина

\section{НЕФТЕГАЗОВЫЕ КОМПАНИИ OIL \& GAS COMPANIES}

Акимов О.В., Кемпф К.В., Набока Р.Р.

АО «АрктикморнефтегазразвеАка» - 40 лет работы на шельфе

Akimov O.V., Kempf K.V., Naboka R.R.

Arktikmorneftegazrazvedka JSC - 40 years on the shelf

\section{ГЕО^ОГИЯ И ГЕОАОГО-РАЗВЕАОЧНЫЕ РАБОТЫ}

\section{GEOLOGY \& GEOLOGICAL EXPLORATION}

Вотинцев А.Н., Мишин О.Ф., АиАковская Г.И.

Признаки неопротерозойского оледенения на эрозионной поверхности фунАамента

Непско-Ботуобинской антеклизы по Аанным ЗD сейсморазведки МОГТ

Votintsev A.N., Mishin O.F., Didkovskaya G.

Traces of the Neoproterozoic glaciation on the erosion surface of the Nepa-Botuoba

anteclise foundation according to the data of the $3 D$ seismic survey by common depth point method

Исказиев К.О., Хафизов С.Ф., Танинская Н.В.

Коншептуальная седиментологическая модель франских

терригенно-карбонатных отложений Чинаревского месторожАения (Казахстан)

Iskaziev K.O. Khafizov S.F. Taninskaya N.V.

Conceptual sedimentological model of clastic-carbonate Frasnian section

on Chinarevskoye field (Kazakhstan)

Полишук А.В., ^ебелев М.В.

Зоны нефтегазонакопления бассейна Солимойнс, суббассейна \Куруа (Бразилия)

по $\Delta$ анным 3D бассейнового мохелирования

Polischuk A.V., Lebedev M.V.

Oil and gas accumulation zones based on 3D basin modeling, Solimoes basin, Jurua sub-basin, Brazil

Курманов О.Е., Мирошкин В.Г., Хайдаров А.С., Штырляева А.А., Гурьевских ^.А., Зайрумин И.И. В^ияние фашиальной неоднородности пласта Ю? на прогноз петрофизических параметров на примере участка Нижневартовского сво $\Delta а$

Kurmanov O.E., Miroshkin V.G., Khaydarov A.S., Shtyrlyaeva A.A., Guryevskikh L.A., Zayrullin I.I.

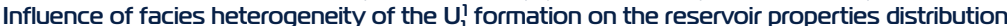

by the example of a part of the Nizhnevartovsk arch

Стовбун Ю.А., Смагина Т.Н., Ульянова В.П., Шевцова Е.Ю., Абрашов В.Н.

Применение фашиального анализа $\Delta$ я решения сложных залач

геологического моделирования на примере Берегового месторожАения

Stovbun Yu.A., Smagina T.N., Ulyanova V.P., Shevtsova E.YU., Abrashov V.N.

Application of facies analysis in solving geomodeling challenges. Case study of Beregovoye field

Парфенов А.Н., ^авров И.В., Аетичевский А.Е., Хвостанцев С.В.

Альтернативные методы геофизических исследований скважин

мля определения азимутов горизонтальных напряжений

Parfenov A.N., Lavrov I.V., Letichevskiy A.E. Khvostancev S.V.

Alternative methods for geophysical well logging to determine the azimuth of the horizontal stresses

\section{УЧАСТНИКИ ИЗААНИЯ ЖКУРНАЛА}

ЗАРУБЕЖНЕФТЬ
БАШНEФTЬ 


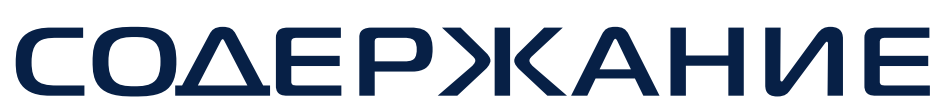 CONTENT}

Кузьмичев О.Б., Жонин А.В., Мартынова Ю.В., Коломасова С.А.

Решение обратной задачи метода потеншиалов самопроизвольной поляризашии в пачке п^астов с зоной проникновения (терригенный разрез)

Kuzmichev O.B., Zhonin A.V., Martynova Yu.V., Kolomasova S.A.

Solution of the inverse problem of self-polarization logging in a pack of layers with a penetration zone (terrigenous section)

Шумейко С.А., Филин Н.Н.

Применение беспилотных летательных аппаратов непрофессионального

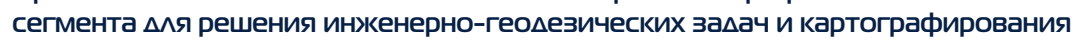
территорий месторожАений

Shumeyko S.A. Filin N.N.

The use of non-professional unmanned aerial vehicle system for the tasks of engineering geodesy and mapping oil and gas fields territory

\section{ИНФОРМАШИЯ}

INFORMATION

\section{АнтониаАи $\triangle . Г$.}

О консолихашии компаний, ученых и спешиалистов нефтегазовой отрасли

мля созАания Российского Нашионального института нефти и газа

Antoniadi D.C.

On the joint efforts of companies, scientists and specialists in the oil and gas industry

to organize the Russian National Institute of Oil and Gas

\section{Новости компаний}

Oil \& Gas News

\section{РАЗРАБОТКА И ЭКСПАУАТАШИЯ НЕФТЯНЫХ МЕСТОРОЖКАЕНИЙ} OIL FIELD DEVELOPMENT \& EXPLOITATION

\section{Хисамов Р.С., Гуськова И.А., ГабАрахманов А.Т., Саяхов В.А., Охотникова Е.С.}

Сравнительный анализ неоднородности состава и свойств сверхвязкой нефти

Ашальчинского месторожАения на основе экспериментальных исслеАований

Khisamov R.S., Guskova I.A., Gabdrakhmanov A.T., Sayakhov V.A., Okhotnikova E.S.

The comparative analysis of heterogeneity composition and properties of extra-viscous oil

of Ashalchinskoye field based on experimental researches

Крыганов П.В., Афанаскин И.В., Вольпин С.Г., Ахапкин М.Ю

Выявление шеликов нефти на основе математического моделирования

и гимродинамических исслеАований скважин

Kryganov P.V., Afanaskin I.V., Volpin S.G., Ahapkin M.Yu.

Identification of the reservoir parts with the bypassed oil on the basis of mathematical

simulation and well tests analysis

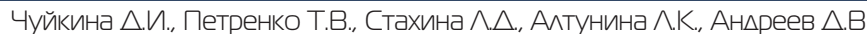

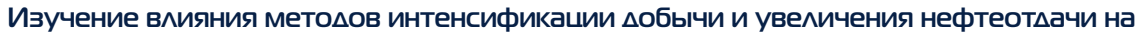

состав и устойчивость нефти Усинского месторожАения

Chuikina D.I., Petrenko T.V., Stakhina L.D., Altunina LK., Andreev D.V.

Studying the effect of improved and enhanced oil recovery methods on the composition

and stability of oil from the Usinskoye oil field
EDITORIAL BOARD

V.N. ZVEREVA (Editor in chief)

I.S. AFANASIEV

N.N. ANDREEVA

A.V. ARZHILOVSKIY

M.D. VALEEV

E.Kh. VEKILOV

M.G. VOLKOV

D.V. VOLOKHOV

A.G. GUMEROV

A.N. DMITRIEVSKIY

A.N. DROZDOV

S.A. ZHDANOV

I.S. ZAKIROV

A.B. ZOLOTUKHIN

R.R. IBATULLIN

N.G. IBRAGIMOV

V.A. KLINCHEV

A.Yu. KORSHUNOV

N.I. KRYSIN

V.Z. KUZENKOV

A.M. KUZNETSOV

A.M. MASTEPANOV

A.G. MESSER

N.N. MIKHAILOV

R.Kh. MUSLIMOV

D.K. NURGALIEV

V.A. SAVELYEV

R.Z. SAKHABUTDINOV

A.S. TIMCHUK

M.M. KHASANOV

A.Kh. SHAKHVERDIEV

G.I. SHMAL

ЗАО «ИзАательство «HЕФТЯНОE X0ЗЯЙСТВО»

(C) “Нефтяное хозяйство”

Зарегистрирован в Министерстве

Российской Федерации

по делам печати,

телерадиовещания и средств массовых коммуникаций РФ 14.10.2002 г

Рег N ПИ №77-13722 
ЗАО «ИзАатеАьство «HЕФТЯНОЕ ХОЗЯЙСТВО»

Генеральный директор,

главный редактор

В.Н. Зверева

Исполнительный директор, заместитель главного редактора О.В. Провоторова

Заместитель главного редактора

В.И. Федорова

Главный бухгалтер

Е.И. Барышева

Бухгалтер

С.Г. Винокурова

Помощник генерального директора И.И. Шоломова

Руководитель редакционной группы В.В. Сулаева

Научные редакторы

Н.В. Елисеева, А.А. Салтыкова

Редактор

Ю.В. Евдошенко

Руководитель группы верстки и дизайна

А.А. Клышникова

Специалист по компьютерной

верстке

Я.А. Морозова

Художник

М.Г. Иванова

Специалист prepress

Г.Д. Мухина

Старший менеджер по рекламе

Ю.Ю. Каминская

Менеджер по рекламе

Н.Ю. Чубаева

Координатор проектов

А.В. Давыдова

Менеджер по связям

с общественностью

А.В. Горбунова

Руководитель информационной группы

Б.И. Потапов

Веб-редактор

С.Ю. Тер-Саакян

Системный администратор

B.Е. Наместников

Сдано в набор 18.09.2019

Подписано в печать 18.10.2019

Формат 64x90, $1 / 8$.

Бумага мелованная

Печать офсетная. Усл.п.л. 7,5

Усл. кр.-отт. 10. Уч-изд.л. 15

Тираж 3000 экз.

Sent for printing 18.09.2019

Passed for printing 18.10.2019

Format $64 \times 90,1 / 8$

Offset printing

Circulation 3000

Отпечатано в типографии "КЕМ" 129626, г. Москва, Графский пер., д. 9 , стр. 2

Цена свободная

Перепечатка статей возможна только с письменного разрешения редакции Редакция не несет ответственности за достоверность информации, опубликованной в рекламных объявлениях

$\triangle$ уркин С.М., Меньшикова И.Н., Рузин А.М., Терентьев А.А

Опыт разработки Аыаельской плошади Ярегского месторожАения

высоковязкой нефти с применением различных технологий

Durkin S.M., Menshikova I.N., Rusin L.M., Terentiev A.A.

Expierence of development of the Liael area of Yaregskoye heavy oil field using different technologies

Зенченко Е.В., Тримонова М.А., Турунтдев С.Б.

^абораторное моделирование гимроразрыва пласта и сопутствуюших прочессов

Zenchenko E.V., Trimonova M.A., Turuntaev S.B.

Laboratory modeling of hydraulic fracturing and related processes

Родионова И.И., Шабалин М.А., Мироненко А.А., Хабибумин Г.И.

Оптимизашия проектных решений и систем заканчивания скважин

при разработке сверхнизкопронишаемых и сверхнеоднородных пластов

Rodionova II Shabalin MA Mironenko A. Khabibullin G.

Field development plan and well completion system optimization for ultra-tight

and ultra-heterogeneous oil reservoirs

\section{ОСВОЕНИЕ ШЕАЬФА \\ OFFSHORE DEVELOPMENT}

Сочнев О.Я., Корнишин К.А., Тарасов П.А., Ефимов Я.О., Гудошников Ю.П., Нестеров А.В.,

Бузин И.В., Свистунов И.А., Максимова П.В

Особенности физического воздействия на айсберги при наличии ^ьАа

на акватории при освоении арктического шельфа

Sochnev O.Ya. Kornishin K.A. Tarasov P.A. Efimov Ya.O.

Gudoshnikov Yu.P., Nesterov A.V., Buzin I.V., Svistunov I.A., Maksimova P.V.

Special aspects of iceberg towing in early ice conditions for arctic shelf development

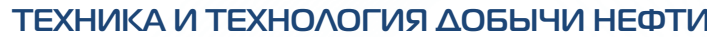

OIL RECOVERY TECHNIQUES \& TECHNOLOGY

Иванов А.Н., Бондаренко В.А., Велиев М.М., Кудин Е.В., Гришенко Е.Н.

Испытание и внедрение установок электрошентробежных насосов

на месторожАении Белый Тигр

vanov A.N., Bondarenko V.A., Veliev M.M., Kudin E.V., Grishchenko E.N.

Test and application of electrical submersible pump units at White Tiger field

Е^агина О.Ю., Агеева В.Н., Буклаков А.Г.

Некоторые аспекты применения теплоизолячионных материалов

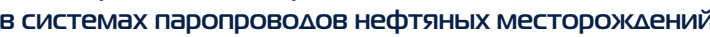

Elagina O.Yu., Ageeva V.N., Buklakov A.C.

Some aspects of heat-insulating materials application on systerns of oil fields steam pipelines

Закиров А.Г., МухамеАшин М.А., Закиров Г.А., Файзрахманов Р.А

Николаев А.Н., Рюмкин А.А

Проблемы и пути повышения энергетической эффективности,

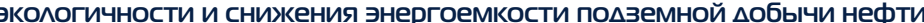

Zakirov D.G., Mukhamedshin M.A., Zakirov G.D., Fayzrakhmanov R.A., Nikolaev A.N., Ryumkin A.A.

Problems and ways to improve energy efficiency, environmental performance

and energy consumption of oil mining

\section{РАЦИОНАЯЬНОЕ ИСПОАЬЗОВАНИЕ НЕФТЯНОГО ГАЗА} RATIONAL USE OF ASSOCIATED PETROLEUM GAS

Вовк В.С. Зайченко В.М. Крылова А.Ю.

Новое направление утилизашии нефтяного газа

Vovk V.S., Zaichenko V.M., Krylova A.U.

New direction of associated petroleum gas utilization

\section{ИНФОРМАШИОННЫЕ ТЕХНОЛОГИИ}

INFORMATION TECHNOLOGIES

Громаков Е.И., Мамонова Т.Е., Миепиньш А.В., Рымшин А.Н.

Развитие перспективной автоматизашии в нефтегазовой отрасли

Gromakov E.I. Mamonova T.E. Liepinsh A.V. Rymshin A.N.

Development of perspective automation in the oil and gas industry

Шель - шифровое управление нефтегазовыми активами

The purpose is digital management of oil and gas fields

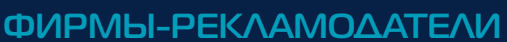

ООО «Газпромнефть НТЧ».....3 стр. о6^.

О०О НПФ «Пакер»......................4 стр. об^.

ООО «Северный сруб» ...............................57

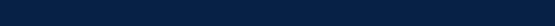

РЕКЛАМНО-ИНФОРМАШИОННАЯ САУКБА:

Филиал ООО «АУКОЙ^-ИнжиниринГ» «КогалымНИПИнефть». 103 АО «Объединенная метаммургическая компания» $.114-116$ 
TРАНСПОРТ И ПОАГОТОВКА НЕФТИ OIL TRANSPORTATION \& TREATMENT

Ахмалеев А.Г., Фам Тхань Винь, Чау Нят Банг, Михайлов А.И.

Обеспечение оптимального сбора и транспорта продукшии малых морских месторожАений

Akhmadeev A.G., Pham Thanh Vinh, Chau Nhat Bang, Mikhailov Al.

Optimal gathering and transportation assurance of well production of small offshore oilfields

\section{Коршак А.А., Гайсин М.Т., Пшенин В.В.}

Использование метода структурной минимизашии среднего риска

м^я иментификашии массоотАачи испаряюшейся нефти при наливе в танкеры

Korshak A.A. Gaisin M.T. Pshenin V.V.

Method of structural minimization of the average risk for identification of mass transfer of evaporating oil at tanker loading

Тулякков А.С., Шигапов Р.P.

Система автоматического Аозирования ингибитора в промысловые трубопрово $ы$

Tulyakov A.S., Shigapov R.R.

Automatic inhibitor dosing in a system of field pipelines

Трубы ВМЗ с ППУ изоляшией не боятся Севера

VSW Pipe with PU foam coating has no fear of the North

ЭКОАОГИЧЕСКАЯ И ПРОМЫШАЕННАЯ БЕЗОПАСНОСТЬ

ENVIRONMENTAL \& INDUSTRIAL SAFETY

Омельянюк М.В., Пахлян И.А.

Разработка и внедрение технологии кавитационно-волновой очистки радиационно загрязненного нефтепромыслового оборудования

Omelyanyuk M.V., Pakhlyan I.A.

Developing and implementing the technology for cavitation-wave cleaning of radiation contaminated oilfield equipment

\section{СорОмотин А.М., СолоАОвников А.Ю.}

Геохимическое состояние почв Аиительно разрабатываемых месторожАений

Среднего Приобья (на примере Родникового месторожления)

Soromotin AM Solodovnikov AY

Geochemical condition of soils of mature oil fields of the Middle Ob (based of Rodnikovoye oil field example)

БогАанович Б.Ю., И^ьинский А.В., Кутузов Е.М., Нестерович А.В.

Сенюков В.А., Шиканов А.Е., Шиканов Е.А.

Обнаружение утечек в полземных нефте- и газопрово $\Delta а х$

Bogdanovich B.Yu., Ilyinsky A.V., Kutuzov E.M., Nesterovich A.V., Senyukov V.A., Shikanov A.E., Shikanov E.A. Detection of leaks in underground oil and gas pipelines

\section{ПАМЯТИ ВЫМАЮШЕГОСЯ НЕФТЯНИКА}

IN MEMORY OF OILMAN IN DISTINCTION

\section{Рузин Леоних Михайлович}

Rusin Leonid Mikhailovich
Editorial staff Publishing House "OIL INDUSTRY"

General Director - Editor in chief

V.N. Zvereva

Executive Director - Vice editor in chief

O.V. Provotorova

04 Vice editor in chief

V.I. Fedorova

Chief accountant

E.I. Barysheva

Accountant

S.G. Vinokurova

Assistant to General Director

I.I. Sholomova

Head of Editor group

V.V. Sulaeva

Scientific editors

112 N.V. Eliseeva, A.A. Saltykova

Editor

Yu.V. Evdoshenko

114 Head of Design and Layout group

A.A. Klyshnikova

Layout specialis

Ya.A. Morozova

Designer

M.G. Ivanova

Pre-press

117 G.D. Mukhina

Senior Advertising manager

Yu.Yu. Kaminskaya

Advertising manager

N.Yu. Chubaeva

Project coordinator

A.V. Davydova

PR manager

A.V. Gorbunova

Head of IT group

B.I. Potapov

26 Web-editor

S.Yu. Ter-Saakyan

System administrator

V.E. Namestnikov

Редакция находится по ацресу: Publishing House Address:

115191, РФ, Москва, ул. Большая Тульская, д. 10, стр. 9, офис 9705

115191, Bol shaya Tul skaya,

10/9, room 9705

Moscow, Russian Federation

+7 (495) 231-1090

+7 (495) 231-1091

mail@oil-industry.ru www.oil-industry.ru
ЕАИНСТВЕННЫЙ отраслевой журнал, который вхоАит в МежАунароАную базу Аанных SCOPUS

В Аекабре 2015 г. журнал «Нефтяное хозяйство» вошел в чис $\wedge$ о 650 ^учших россиЙсКИХ научных журнслов и размещен на платформе Web of Science в составе базы Russian Science Citation Index (RSCl)

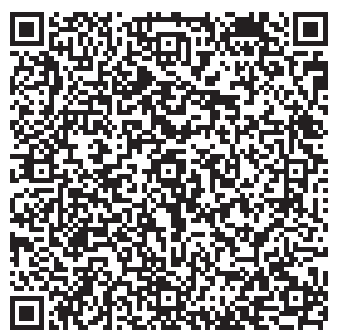

